\title{
Development of Flat Slab - Column Interaction with Different Thickness
}

\author{
Ilya Binti Joohari ${ }^{1, *}$, and Norliyati Binti Mohd Amin ${ }^{2}$ \\ ${ }^{1}$ School of Environmental Engineering, Universiti Malaysia Perlis, 02600 Arau, Malaysia \\ ${ }^{2}$ Faculty of Civil Engineering, University Teknologi MARA, 40450 Shah Alam, Malaysia
}

\begin{abstract}
Flat slab - column connection has received much attention in recent years due to its simplicity of construction where beam is not required to support the slab. Flat slab has many usages in the construction field and has been investigated as a potential building material. Despite its many benefits, flat slab is easily subjected to punching shear failure. A simple approach to minimize punching shear failure is by increasing the slab thickness. It is generally accepted that the performance of flat slab is improved by using shear reinforcement; however, little attention has been paid to the selection of thickness. This research focuses on the crack behaviour of flat slab due to different slab thickness. Two specimens with different slab thickness have been constructed and tested to obtain the flat slab strength and crack pattern behaviour. Increasing the slab thickness was found to improve the strength of the flat slab and minimize the deflection and crack appearance on the slab.
\end{abstract}

\section{Introduction}

All A flat slab is a reinforced concrete slab that is supported directly by concrete columns without the use of beams [1]. It is widely used nowadays due to the many advantages it offers. One of the biggest contribution of flat slab is it allows faster construction [2]. It can be built faster because the formworks are simplified and reduced. Another highlight of using flab slab is it gives flexibility in room layout. It allows architect to introduce partition walls anywhere required and for owners to change the size of room layout. Flab slab also saves the building in height. It approximately saves $10 \%$ in vertical members, thus reducing foundation load [3].

Besides its various advantages, flat slab still has a weak point. It is susceptible to punching [4]. Punching shear is a type of failure when reinforced concrete slabs are subjected to localized forces. In flat slab structure, punching shear occurs at support column point. Punching shear can occur without any warning when the slab is subjected to extensive loading [5]. It can cause serious cracking and deflections.

To reduce the risk of punching shear in flat slab, a wide range of methods have been proposed. There are mainly two ways to increase the punching shear strength of concrete slabs which is by increasing the slab thickness in the vicinity of the column by providing a drop panel or a column head or second is by providing shear reinforcement [6].

\footnotetext{
* Corresponding author: ilya@unimap.edu.my
} 
Conventionally, shear reinforcement can be in the form of stirrups or bent-up bars. However, these types of shear reinforcement have proven not to be very effective, especially in thin slabs (150-250 mm in overall thickness). Another down grade of this method is it is time consuming for construction. Recently, using steel fibers to strengthen the slab have been introduced [7]. Since it is quite new, it is rarely used in Malaysia. Thus, another practical and easy method is by increasing the slab thickness to increase its strength.

This research, based on experimental program done by other researchers on various methods, discusses the maximum shear strength of flab slab - column connection and the crack behavior for slab with different thickness. It also presents and compares the results for these two slabs.

\section{Experimental work}

This research is conducted to test the strength of flat slab-column connection when subjected to punching shear. A total of two flat slabs - column connection were fabricated for this research. The size of flat slab tested was $1 \mathrm{~m}$ x $1 \mathrm{~m}$ with thickness $100 \mathrm{~mm}$ for Sample 1 . The column connected to the slab is of size $0.2 \mathrm{~m} \times 0.2 \mathrm{~m}$ with height $0.15 \mathrm{~m}$. The column is constructed just on top of the flat slab and exactly in the middle. The concrete grade used is $\mathrm{C} 25$. Steel bar of 7Y10 is used as the bottom reinforcement for both $\mathrm{X}$ and $\mathrm{Y}$ directions. The cover designed is $10 \mathrm{~mm}$. Meanwhile, Sample 2 is fabricated with the exact same dimensions and material properties but only with different slab thickness which is $120 \mathrm{~mm}$. No shear reinforcement is added to both samples. The laboratory test was focused on obtaining the maximum load value for both specimens and observing the very first crack pattern to the very last crack pattern.

The material used for this concrete is ordinary Portland cement (OPC), sand, aggregate and tap water. The ratio of concrete mix is 1:1: 2 which are for cement, sand and aggregate respectively. The size of sand is $2 \mathrm{~mm}$ and the size of aggregate is $16 \mathrm{~mm}$. Both samples were concreted using the same concrete batch to ensure identical properties. The same concrete mix is also poured into a $150 \mathrm{~mm} \times 150 \mathrm{~mm} \times 150 \mathrm{~mm}$ cube mould to be tested for compressive strength of concrete. The design concrete strength is grade 25 . Table 1 shows the material properties for both samples.

Table 1. Material Properties

\begin{tabular}{|l|l|}
\hline \multicolumn{2}{|c|}{ Properties } \\
\hline Type of cement & Portland \\
\hline Size of sand & $2 \mathrm{~mm}$ \\
\hline Size of aggregates & $16 \mathrm{~mm}$ \\
\hline Ratio of concrete mix & $1: 1: 2$ \\
\hline Water - cement ratio & 0.5 \\
\hline Grade concrete & $25 \mathrm{~N} / \mathrm{mm}^{2}$ \\
\hline
\end{tabular}

The samples are loaded onto a support, ensuring the effective length of span to be $0.8 \mathrm{~m}$ by $0.8 \mathrm{~m}$. Four concrete strain gauges are installed on the surface of the samples. The function of the strain gauges is to measure the amount of stresses generated. Two linear variable differential transformers (LVDT) are used to measure the deflections of the slab. The two LVDT's are placed at the bottom side and on one side of the slab respectively to measure vertical and horizontal displacement. Load increment of $2.5 \mathrm{~mm} / \mathrm{min}$. is subjected on top of the column acting as vertical load. The samples are loaded continuously until failure. 


\section{Experimental result}

Prior work has been documented that increasing the slab thickness with shear reinforcement improves the strength of flat slab column connection in terms of punching shear capacity. Bompa and One [1], for example, reported that the flat slab column connection with shear reinforcement improves the punching shear capacity. However, these studies have been focusing on the usage of shear reinforcement on large scale samples. In this study, the main focus is on the slab thickness of a smaller scale sample without the usage of shear reinforcement.

It is found that after testing, increasing the slab thickness even without shear reinforcement improves the strength, reduces the deflection and crack pattern on the flat slab surface. Sample 1 and Sample 2 were compared in terms of their maximum loading, deflection and crack pattern behaviour.

\subsection{Load - Displacement Graph}

Fig.1 shows the load - displacement graph which is obtained from the samples tested. The results of the load at first crack and ultimate failure load are tabulated in Table 2 and 3 respectively.

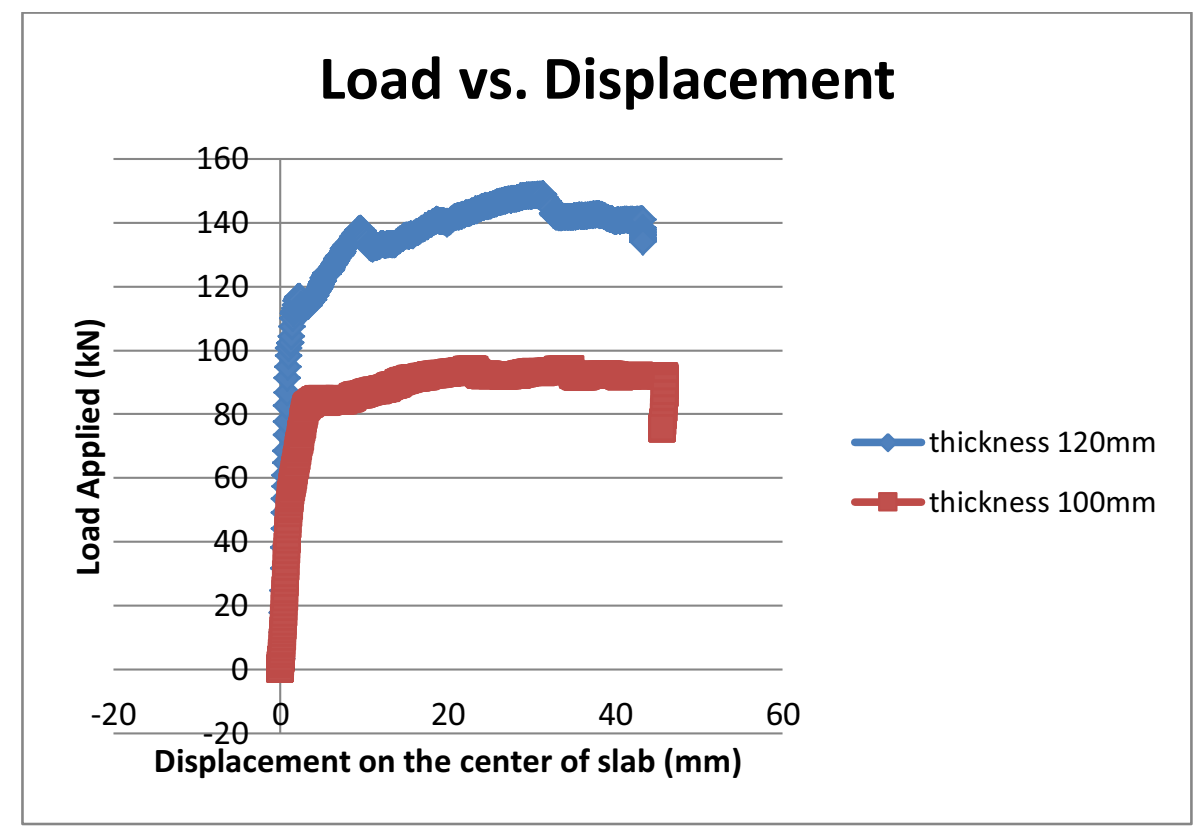

Fig. 1. Load vs. vertical displacement for Sample 1 and Sample 2

Table 2. Load at first crack

\begin{tabular}{|c|c|c|}
\hline Name of Sample & Thickness of slab $[\mathrm{mm}]$ & Load at first crack $[\mathrm{kN}]$ \\
\hline Sample 1 & 100 & 65 \\
\hline Sample 2 & 120 & 112 \\
\hline
\end{tabular}


Table 3. Ultimate failure load

\begin{tabular}{|c|c|c|}
\hline Name of sample & Thickness of slab [mm] & Ultimate failure load [kN] \\
\hline Sample 1 & 100 & 93.92 \\
\hline Sample 2 & 120 & 148.81 \\
\hline
\end{tabular}

The load applied on the structure causes the slab to deflect by hogging where the top part of the structure element is in compression and the bottom part is in tension. The tension failures in the structural element lead to the crack formation in the slabs.

It can be observed that Sample 2 has a higher load value at first crack compared to Sample 1 by $72.3 \%$. The first crack for Sample 2 occurs at a load of $112 \mathrm{kN}$ and at a displacement of $2.63 \mathrm{~mm}$. $65 \mathrm{kN}$ was the load value for Sample 1 at its first crack at a displacement of $1.96 \mathrm{~mm}$. This shows that Sample 2 has a higher punching shear capacity for load at first crack. From the above discussion it is clear that an increase in slab thickness will result in a higher first crack load value.

From Table 3 it is observed that Sample 2 possess higher ultimate failure load compare to Sample 1. Sample 2 with thickness $120 \mathrm{~mm}$ show $148.81 \mathrm{kN}$ to cause ultimate failure, which is a higher load in comparison with Sample 1. Sample 1 with slab thickness $100 \mathrm{~mm}$ shows lesser value which is $93.92 \mathrm{kN}$. This confirms that Sample 2 is superior to Sample 1 for load at ultimate failure. Sample 2 shows an increase of punching shear capacity compare to Sample 1 . The increase is about $58.4 \%$ in punching shear strength for ultimate load failure.

\subsection{Crack pattern behaviors}

Both samples were tested by being loaded under a centric vertical load right on top of the column. Cracks propagations were recorded to study the effect of punching shear capacity with crack patterns developed. Both samples failed in punching shear. For illustration, photos of the crack patterns on the bottom face of Sample 1 and 2 are shown in Fig.2 respectively.
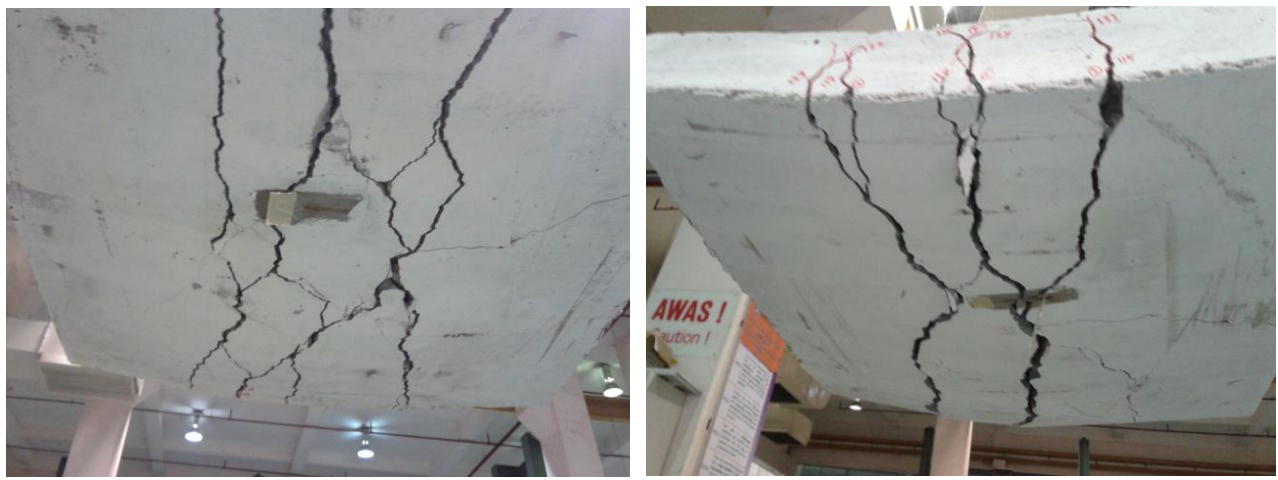

Fig. 2. Crack patterns for Sample 1 (left) and Sample 2 (right).

The crack development in both slabs followed a similar pattern at the early stage of loading. It is observed that the first crack originated at the center and gradually propagate radially towards the sides of the slab. The crack was firstly recorded at the side of slab was right at the center of the side at about $65 \mathrm{kN}$ for Sample 1 and $112 \mathrm{kN}$ for Sample 2. As the load applied was increased, the cracks became wider and more visible at the sides and bottom face of both samples. At the same time new cracks are formed. Besides longitudinal cracks, a circular crack area beneath the slab can be observed clearly after ultimate load failure.

Both samples failed in a brittle manner because no shear reinforcement was used. However, in terms of overall crack patterns, Sample 1 with slab thickness of $100 \mathrm{~mm}$ failed 
more severely compared to Sample 2 with slab thickness of $120 \mathrm{~mm}$. A higher number of radial cracks were observed for sample 1 compare to sample 2 . This can be concluded that increasing the slab thickness will increase punching shear capacity, thus decreasing crack formations.

\section{Conclusion}

Test results showed that all the specimens failed due to punching shear. The increase of slab thickness for the slab - column connection was effective and had improved and increased the maximum load applied and loads at first crack by $36.89 \%$ and $72.3 \%$ respectively. On the other hand, the test resulted in a decrease of $5.9 \%$ of deflection when using thicker slab.

In terms of crack, an increase in slab thickness has resulted in a decrease in the numbers of radial cracks. The surface failure of tested specimens' forms more severely overall crack patterns with thinner slab structure. Besides that, the distance between the column face and surrounding failure crack was larger in case for higher slab thickness.

Increasing slab thickness in design provides option to engineers to eliminate the use of shear reinforcement to increase punching shear capacity as installing shear reinforcement is more consuming for the project. In addition, increasing slab thickness allows designer to avoid using drop panels which can be a major architectural minus.

This work was financially supported by Universiti Malaysia Perlis.

\section{References}

1. D.V. Bompa, T. One, Fib Symposium Tel-Aviv 2013, (2013)

2. D.V. Bompa, T. One, Technical University Of Cluj Napoca, (2011)

3. D.V. Bompa,T. One, Behaviour of Symmetric Flat-Slab Connections with Openings in the Control Perimeter (Cluj-Napoca, Romania, 2010)

4. D.J.O. Cueva, I.N. Robertson, Retrofit of Flat-Slab Column Connections Using CFRC Studs to Resist Punching Shear from Cyclic Loading (Research Report, 2008)

5. R.B. Gomes, P.E. Regan, Journal of Structural Engineering, (1999)

6. H. Guan, Y.C. Loo, Can. J. Civ. Eng, 30, 934 (2003)

7. M.A. Polak, Ductility of Reinforced Concrete Flat Slab-Column Connections Department of Civil Engineering (Blackwell Publishing, Canada, 2005) 